\title{
Marmosets: a promising model for probing the neural mechanisms underlying complex visual networks such as the frontal-parietal network
}

\author{
Joanita F. D'Souza ${ }^{1,2} \cdot$ Nicholas S. C. Price ${ }^{1,2} \cdot$ Maureen A. Hagan ${ }^{1,2}$ (1) \\ Received: 1 April 2021 / Accepted: 23 August 2021 / Published online: 13 September 2021 \\ (c) The Author(s) 2021
}

\begin{abstract}
The technology, methodology and models used by visual neuroscientists have provided great insights into the structure and function of individual brain areas. However, complex cognitive functions arise in the brain due to networks comprising multiple interacting cortical areas that are wired together with precise anatomical connections. A prime example of this phenomenon is the frontal-parietal network and two key regions within it: the frontal eye fields (FEF) and lateral intraparietal area (area LIP). Activity in these cortical areas has independently been tied to oculomotor control, motor preparation, visual attention and decision-making. Strong, bidirectional anatomical connections have also been traced between FEF and area LIP, suggesting that the aforementioned visual functions depend on these inter-area interactions. However, advancements in our knowledge about the interactions between area LIP and FEF are limited with the main animal model, the rhesus macaque, because these key regions are buried in the sulci of the brain. In this review, we propose that the common marmoset is the ideal model for investigating how anatomical connections give rise to functionally-complex cognitive visual behaviours, such as those modulated by the frontal-parietal network, because of the homology of their cortical networks with humans and macaques, amenability to transgenic technology, and rich behavioural repertoire. Furthermore, the lissencephalic structure of the marmoset brain enables application of powerful techniques, such as array-based electrophysiology and optogenetics, which are critical to bridge the gaps in our knowledge about structure and function in the brain.
\end{abstract}

Keywords Marmosets $\cdot$ Neural circuits $\cdot$ Visual attention $\cdot$ Saccades $\cdot$ Optogenetics $\cdot$ Frontal cortex $\cdot$ Parietal cortex

\section{Introduction}

Understanding the neural mechanisms underlying cognitive functions has proven to be a difficult feat for the field of neuroscience. The overwhelming majority of systems neuroscience experiments have focused on the contribution of individual brain areas to a particular behaviour or cognitive process. In practice, no brain area works in isolation. Networks of brain areas work together-wired together with precise anatomical connections-to carry

Maureen A. Hagan

maureen.hagan@monash.edu

1 Department of Physiology and Neuroscience Program, Biomedicine Discovery Institute, Monash University, 26 Innovation Walk, Clayton, VIC 3800, Australia

2 Australian Research Council, Centre of Excellence for Integrative Brain Function, Monash University Node, Clayton, VIC 3800, Australia out high-level brain functions. A prime example of this is the frontal-parietal network, which comprises a cluster of areas across the frontal and posterior parietal cortices (PPC), that have been tied to a wide range of behavioural and cognitive processes including oculomotor control, motor preparation, visual attention, and decision-making (Wurtz and Mohler 1976; Colby et al. 1996; Kustov and Robinson 1996). In this review, we focus on two key areas within the frontal-parietal network: the frontal eye fields (FEF) and the lateral intraparietal area (area LIP), both of which have been tied to the control of brief, rapid exploratory eye movements known as saccades. On the surface, both the FEF and area LIP appear to have largely overlapping functional roles, but the contribution of each of these nodes independently, still remains unknown. We have specifically chosen to discuss the LIP-FEF path in association with oculomotor processes, because saccadic eye movements are a simple and effective way of probing visual behaviour and attention. However, the common 
marmoset (Callithrix jacchus), like the rhesus macaque (Macaca mulatta) and humans, display coordinated eye-hand behaviours (Hook and Rogers 2008), and areas of their frontal cortex suggest some anatomical similarities to macaque motor and premotor reach and grasp areas (Burman et al. 2014a, b). This suggests that they may also be a suitable model for some visually guided reaching behaviours as well, although with some important caveats (see (Bakola et al. 2015) for a review).

Non-invasive techniques that allow for whole brain studies, such as functional magnetic resonance imaging (fMRI) and magnetoencephalography (MEG) have been useful in looking at network interactions, but are limited either spatially or temporally, making it impossible to draw conclusions at the level of precise anatomical connectivity. While voltage and calcium-sensitive dyes have permitted valuable measurements and analysis of large populations of neural activity at once, these techniques are sub-optimal for investigations into network activity and interactions between cortical areas. In recent years, multi-area electrophysiology studies aimed at addressing this gap by recording neural activity during visual behaviours have become more common (Saalmann et al. 2007; Dean et al. 2012; Siegel et al. 2015; Wong et al. 2016). However, these techniques largely only permit correlational conclusions to be drawn about the neural activity that accompanied cognitive functions. To claim that a particular region plays a causal role in the generation of a cognitive function, the activity of individual neurons must be perturbed to observe the direct effects on cognitive functions and behaviour (Parker and Newsome 1998). Traditionally, this has been achieved through invasive techniques, such as electrical stimulation or cortical lesions, induced via pharmacological manipulations or cooling methods. While these techniques are extremely valuable, they lack the temporal and spatial precision necessary to study functional contributions of specific cell types and their interactions with other brain regions. Often, they non-selectively involve large regions of cortex, simultaneously activating all output pathways in a region. Designer receptors exclusively activated by designer drugs (DREADDs), a technique that can control molecularly defined subsets of cells through engineered G-protein-coupled receptors, overcomes the spatial resolution limitations of these aforementioned techniques, but sacrifices temporal resolution. DREADDs operate in the range of minutes to hours, modulating neuronal activity in a much more prolonged fashion (reviewed in (Whissell et al. 2016). Currently, optogenetics is the only technique with both high temporal and spatial resolution, offering a way in which to target and control precise cell types in vivo, on a millisecond time-scale (Boyden et al. 2005; Deisseroth 2011). By genetically modifying specific types of neurons and causing them to express light-sensitive membrane proteins known as opsins, this technique enables precise, targeted control of neural circuits with specific wavelengths of light that can be delivered from outside an intact dura.

One current limitation in connecting these technologies to visual and cognitive behaviours is the choice of animal model. Rodents have been the primary animal model for the development of new molecular technologies, but they lack homologous cortical networks to humans and rely far less on their vision. Primates, on the other hand, predominantly use their vision and saccadic eye movements to monitor and interact with their environment. The macaque monkey in particular, has been the main source for understanding cognitive visual behaviour, because its cortical networks, including the frontal-parietal, are remarkably similar to humans. However, in macaques, many key areas of interest, including parts of FEF and area LIP, are buried within the sulci of the brain, making access challenging, particularly for precise neural stimulation, multi-electrode laminar recordings, and imaging studies.

Recently, the common marmoset, a small-bodied New World primate, has gained popularity as a primate model for neurophysiology research (Solomon and Rosa 2014; Mitchell and Leopold 2015). Among their many advantages, marmosets have a small body and fast reproduction cycles, making them amenable to transgenic technology (Sasaki et al. 2009). The anatomical subdivisions of cortical areas in the marmoset have also been mapped, and their anatomical connections are consistent with humans and macaques (Rosa et al. 2009; Majka et al. 2016, 2020). Furthermore, marmosets have a rich behavioural repertoire consisting of both natural (Miller and Wren Thomas 2012) and conditioned (Mitchell et al. 2014, 2015) tasks. Marmosets also rely strongly on their sense of sight - a fact that is reflected in the large fraction of their neocortex dedicated to visual processing (Rosa et al. 2009; Majka et al. 2016, 2020) and their highly developed visual system that is homologous to higher-order primates like humans and macaques (Chaplin et al. 2013; Zhu and Vanduffel 2019). Compared to humans and other primate models, marmosets have a relatively small brain size, which may be a limitation in their use for studying cognitive behaviour. However, in the evolutionary development of primate brains, the differential expansion of cortical areas has largely been conserved across primate species relative to brain size (Chaplin et al. 2013; Zhu and Vanduffel 2019). This means that changes in cortical expansion from marmoset to macaque in a given cortical area (Fig 1A, B) are predictive of the expansion expected from macaque to human. Some areas of cortex have expanded greatly with brain size, such as the ventrolateral prefrontal cortex and temporal parietal junction, which in humans are related to high-level cognitive functions including speech and communication (Fig 1C, red regions). Conversely, areas of the PPC (containing area LIP), scale more modestly between marmosets and macaques (Fig 1C, dorsal view, arrow), and 


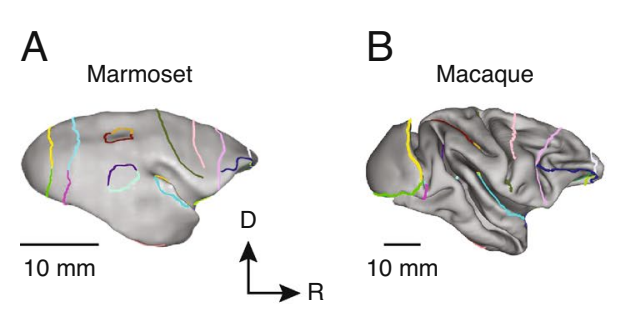

Fig. 1 Expansion of frontal-parietal areas are conserved in primate evolution. A Marmoset and $\mathbf{B}$ macaque brains with identified landmarks which served as anchor points to calculate expansion of cortex across species. Notably, the IPS (maroon) and anterior border of area $8 \mathrm{aV}$ (lavender) were used. C Expansion map projected onto

the expansion of early-developing visual areas like V1 is even more modest (Fig 1C, dorsal view, dark blue regions). This suggests that marmosets may still be a useful model for studying many visual behaviours, despite their small brain size.

Recent research has also confirmed that marmosets can be trained to perform a wide range of visual, oculomotor and cognitive tasks while head restrained, in a manner comparable to macaques and humans (Mitchell et al. 2014, 2015; Johnston et al. 2019; Cloherty et al. 2020). The marmoset brain also has major advantages over rodents and other primate models for neurophysiological research. Critically, the surface of the marmoset brain is lissencephalic, exposing nearly all of its visual cortex on the lateral surface just below the skull, enabling direct access to many high-level brain areas-including important visual and oculomotor areas - that do not have clear homologues in the rodent and that are otherwise buried deep in sulci in primates like the macaque. This facilitates optical imaging and permits precise perpendicular penetrations of cortical layers for laminar analysis of local microcircuits in higher-order visual areas, such as FEF and area LIP, that are normally hidden in sulci. It also enables large-scale neuronal recordings over entire cortical areas, uninterrupted by sulci and permits access to multiple cortical areas simultaneously (Isa 2017). As such, marmosets serve as an important experimental bridge by which advances in the mouse community can be applied to the primate brain.

Acknowledging that the viability of marmosets for studies on the visual system has been previously reviewed (Solomon and Rosa 2014; Mitchell and Leopold 2015), here, we extend upon and update this body of knowledge, by specifically examining why marmosets are an ideal model for untangling the neural mechanisms underlying inter-area interactions in the visual system. Using the frontal-parietal network as an example in marmosets, we will explore what is currently known about the structure and function of key nodes in this network, and how emerging technology, such as optogenetics, may be used to dissect the function of neural circuits.

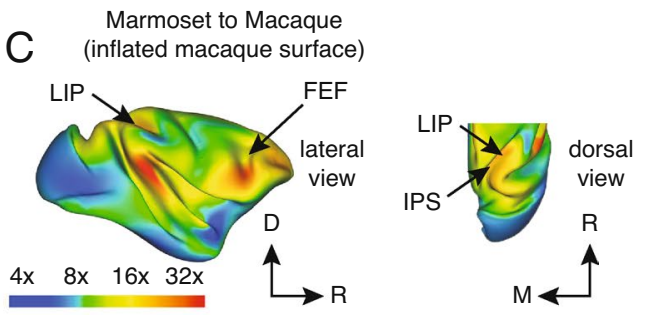

the surface of an inflated macaque brain showing the lateral view of cortex and a dorsal view of the posterior parietal cortex. Color scale indicates the factor of expansion. D, dorsal; M, medial; R, rostral. Adapted from (Chaplin et al. 2013)

\section{Key areas in the frontal-parietal network are conserved in marmosets and macaques}

Areas of the frontal-parietal network have been largely defined based on function, and do not precisely overlap with cyto-architecturally defined boundaries. Furthermore, sulcal folding in the brains of higher-order primates, such as humans and macaques, makes precise anatomical reconstructions challenging. For example, FEF in primates is defined functionally by the ability to induce and influence saccades via micro-stimulation. In macaques, FEF is likely composed of cytoarchitectural areas $45,8 \mathrm{aV}$, and 6 (Bruce et al. 1985; Stanton et al. 1989; Schall et al. 2020), which have anatomical connections with the parietal and visual cortices (Schall et al. 1995) and connections with the superior colliculus both directly (Fries 1984) and via the pulvinar (Sommer and Wurtz 2006; Berman et al. 2009). Projections from FEF to the PPC are dense, feedback projections (Stanton et al. 1995; Schall et al. 1995). Area $8 \mathrm{aV}$ is characterized by large pyramidal neurons in layer $\mathrm{V}$, and at least partially overlaps with the region in which micro-stimulation evokes saccadic eye movements (Stanton et al. 1989). In marmosets, the precise anatomical boundaries of FEF are still being established. However, converging evidence suggests that a similar group of cytoarchitectural areas is involved. Anatomically, areas $8 \mathrm{aV}$ and $6 \mathrm{DR}$ form monosynaptic reciprocal connections with extra-striate visual areas and the posterior parietal cortex (Burman et al. 2006; Reser et al. 2013). One anatomical tracing study has identified neurons in the frontal cortex of the marmoset that project to the superior colliculus (Collins et al. 2005). The region appears to correspond roughly to marmoset area 8 , however, this study did not register to precise cytoarchitectural areas and their injections spanned superficial to deep layers of the superior colliculus. More detailed anatomical studies are needed to fully map out the marmoset cortico-collicular circuits associated with oculomotor behaviours.

In 1874, Ferrier and colleagues were the first to unilaterally stimulate FEF in anaesthetised macaques and elicit 
Fig. 2 FEF-like responses in the marmoset prefrontal cortex. A Example marmoset MRI reconstruction of array recording locations aligned to cytoarchitectural boundaries and B Electrode map for example showing location of saccade, blink and smooth pursuit responses in response to microstimulation. Red arrows indicate amplitude of evoked saccades. Adapted from (Selvanayagam et al. 2019). C Example marmoset MRI reconstruction of array recording locations aligned to cytoarchitectural boundaries and $\mathbf{D}$, Electrode map showing location of visual responses according to cytoarchitectural area. Adapted from (Feizpour et al. 2021). M, medial; R, rostral

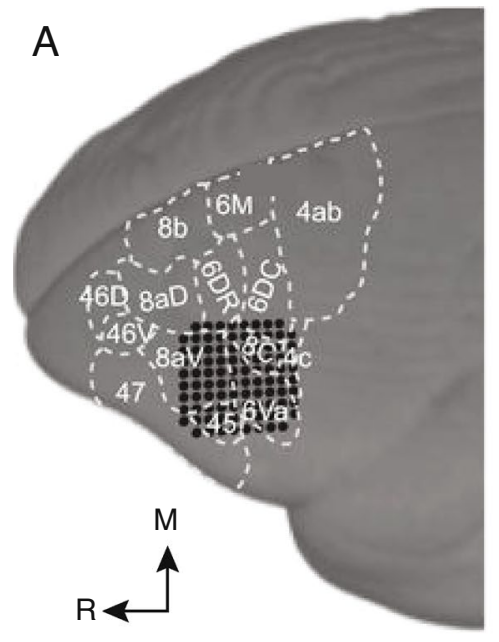

B
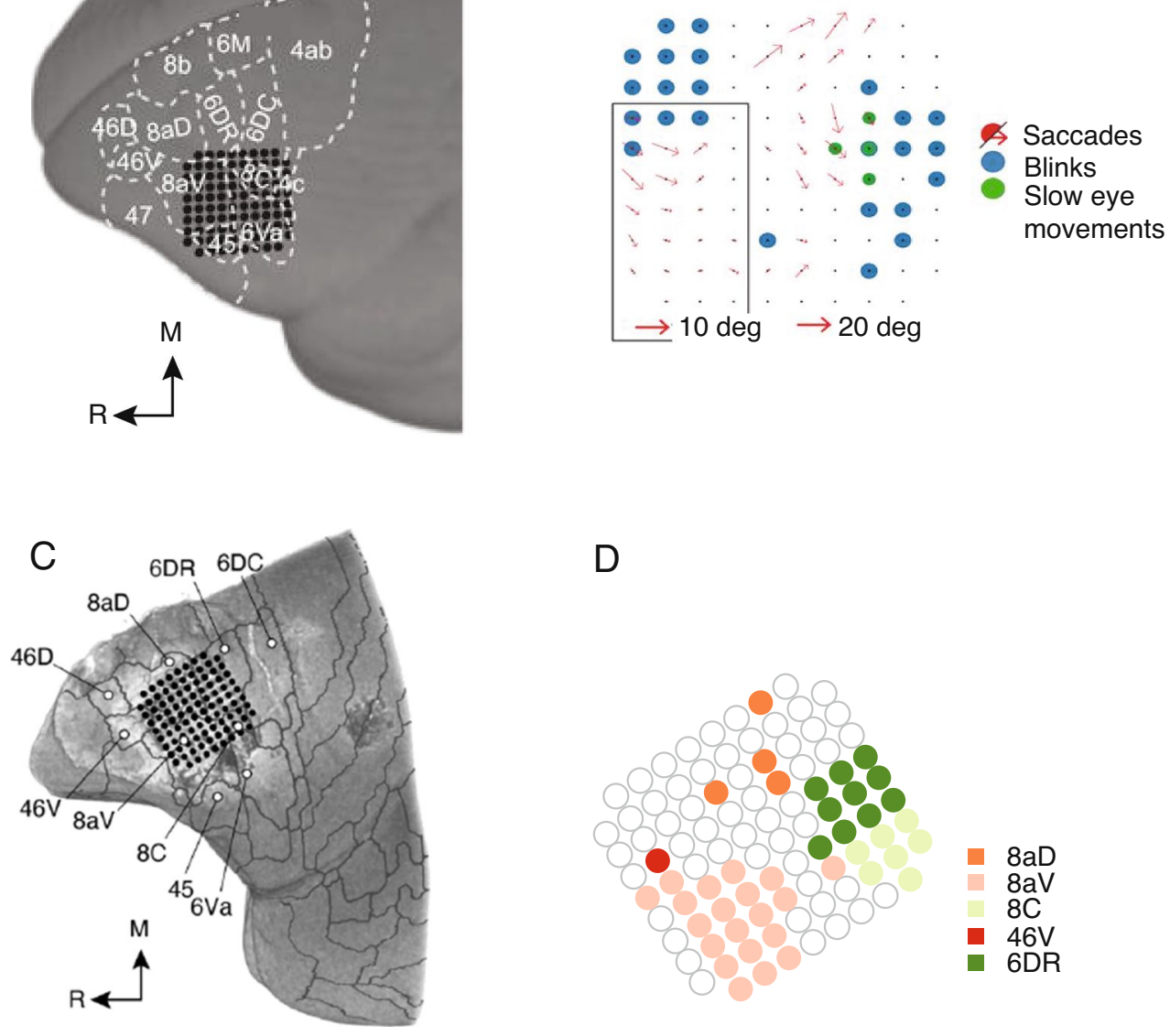

Blinks

Slow eye

movements

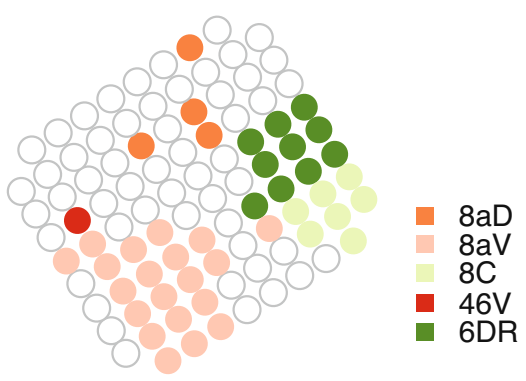

rapid contralateral eye movements known as saccades (Ferrier 1874). This general finding that a brief stimulation of FEF produces a single contralateral saccade, of a particular amplitude, direction, latency and threshold, was reliably replicated by several other groups in the coming years, and in both humans and awake non-human primates (Robinson and Fuchs 1969; Wurtz and Mohler 1976; Bruce et al. 1985; Schmolesky et al. 1998; Schall et al. 2020). One notable study stimulated FEF in over 300 locations and noticed that the amplitude and direction of saccades changed in a stereotyped pattern, depending on where and how FEF was stimulated (Robinson and Fuchs 1969). Evoked saccades in FEF also follow a visual topography - smaller, more foveal saccades are evoked from stimulation of the ventrolateral regions and larger, more peripheral saccades in the dorsomedial regions of FEF (Bruce et al. 1985).

Consistent with macaque literature, electrical stimulation of several frontal cortical sites in marmosets evokes eye and head movements (Mott et al. 1910; Blum et al. 1982). Recently, the dorsolateral prefrontal cortex of awake, free-viewing marmosets was electrically stimulated using a 96-channel Utah array (Selvanayagam et al. 2019). By co-registering their recordings with anatomical MRIs, they were able to provide precise reports of cytoarchitectural areas. In addition to evidence placing marmoset FEF in a similar relative location within oculomotor areas 45 and $8 \mathrm{aV}$ (Burman et al. 2006; Reser et al. 2013; Schaeffer et al. 2019), Selvanayagam and colleagues (2019) found that like human (Silver and Kastner 2009; Jerde and Curtis 2013) and macaque FEF (Bruce et al. 1985; Schall et al. 1995), marmoset FEF is organised in a topographical manner, according to saccade direction and amplitude. Area 45 and the lateral portion of $8 \mathrm{aV}$ were associated with smaller, more foveal saccades (Fig. 2A, B), and saccade amplitudes increased medially across the array, spanning areas $8 \mathrm{aV}$ and 6DR. In marmosets, the saccades evoked by area 6 stimulation tend to be goal-directed in contrast to vector coding of area $8 \mathrm{aV}$, which is similar to the cortical eye fields in macaques (Selvanayagam et al. 2019). Among the few differences between marmosets, humans and macaques, saccade latencies in 
marmosets at low currents were noted to be longer and more variable. It is worth noting that there is some discrepancy in the cytoarchitectural definition of area 45 between humans and monkeys. Both macaque (Schall et al. 1995) and marmoset (Selvanayagam et al. 2019) studies have suggested that as small amplitude saccades can be evoked from area 45, it likely comprises the ventral portion of the FEF. Area 45 in these studies is defined using Walker's definition (Walker 1940), as large pyramidal cells in layers III and V (Schall et al. 1995; Burman et al. 2006; Reser et al. 2013). In humans, area 45 is characterized by large pyramidal cells in layer III but not layer V (Petrides and Pandya 2002). Cells in area 45 by this definition likely do not have non-oculomotor functions (Petrides et al. 2005).

In addition to evoking saccades, a subset of macaque FEF neurons have visual responses, with large receptive fields (Wurtz and Mohler 1976; Cavanaugh et al. 2012) and brisk response latencies (Mohler et al. 1973; Thompson et al. 1996; Schmolesky et al. 1998). Despite FEF's relatively late position in the visual hierarchy, visual responses in FEF have short latencies, comparable to early visual areas such as visual area 2 (V2), which may be due to direct connections with the visual cortex or connections that bypass the hierarchy from the superior colliculus via the thalamus. Similar visual responses can be found in marmosets, particularly in areas 8aV, 8C and 6DR (Fig. 2C, D; (Feizpour et al. 2021)). In macaques, the lateral portion of FEF receives afferents from more foveal representations of visual cortex, while the medial portion receives afferents from peripheral representations of visual cortex (Schall et al. 1995). The same is true for area $8 \mathrm{aV}$ in marmosets (Reser et al. 2013). Consistent with this, in marmosets, the central visual field was better represented by the lateral aspect of area $8 \mathrm{aV}$ and the peripheral visual field was better represented by the medial aspect of area $8 \mathrm{aV}$ (Feizpour et al. 2021).

The FEF is not the only specialised region of the frontal-parietal network that contributes towards visual behaviours. In the PPC, area LIP has been implicated in guiding saccadic eye movement control (Andersen et al. 1985, 1990b). Specifically, area LIP neurons respond to the presentation of behaviorally-relevant visual stimuli in localised regions of space (Gottlieb et al. 1998; Kusunoki et al. 2000) and saccade planning (Mazzoni et al. 1996). In macaques, area LIP is buried in the lateral bank of the intraparietal sulcus within the PPC, and has direct reciprocal anatomical connections to other nodes in the saccade control network such as FEF and the superior colliculus (Huerta et al. 1987; Andersen et al. 1990a; Blatt et al. 1990; Schall et al. 1995; Stanton et al. 1995; Paré and Wurtz 1997; Anderson et al. 2011). In fact, micro-stimulation of FEF in macaques elicits an enhanced fMRI activation of area LIP neurons (Premereur et al. 2013) during visually guided saccade tasks, fixation tasks and even in absence of any visual stimulation
(Ekstrom et al. 2008). The laminar distribution of neurons and the dorsal-ventral subdivisions and myelination patterns of marmoset area LIP are similar to those in macaques (Rosa et al. 2009). Anatomical studies in marmosets have also triangulated connectivity between area LIP, FEF and the superior colliculus, reflecting observations in the macaque visual system (Collins et al. 2005; Reser et al. 2013; Ghahremani et al. 2017).

Like FEF, micro-stimulation of area LIP neurons evokes eye blinks and saccadic eye movements of a particular direction and amplitude in macaques (Shibutani et al. 1984; Thier and Andersen 1998; Hanks et al. 2006) and marmosets (Ghahremani et al. 2017). Electrophysiological recordings in macaque area LIP have also revealed that most neurons discharge in the 'planning stage', just prior to the execution of saccades towards visible and remembered visual targets (Gnadt and Andersen 1988; Barash et al. 1991; Colby et al. 1996; Meister et al. 2013) within their response fields. For example, during saccade tasks where the end target onset is delayed after the fixation target disappears, a "gap effect" of shorter saccade reaction times coupled with an increase in neural activity during the gap period has been recorded in macaques (Chen et al. 2013, 2016) as well as marmosets (Ma et al. 2020). Generally, area LIP neurons respond to a combination of visual stimuli, eye position and the direction and amplitude of planned eye movements, to encode the location of salient visual stimuli in eye-centered or headcentred coordinates (Andersen et al. 1985, 1990b).

Neural activity in the PPC, and notably area LIP has also been shown to be modulated by cognitive factors like visual attention (Goldberg et al. 1990; Colby et al. 1996; Snyder et al. 1997; Corbetta et al. 1998; Colby and Goldberg 1999; Bisley and Goldberg 2003, 2010), reward (Platt and Glimcher 1999; Sugrue et al. 2004) and decision-making (Gold and Shadlen 2000; Wong et al. 2016; Hawellek et al. 2016). Area LIP is thought to integrate bottom-up sensory and top-down cognitive factors by combining and transforming visual information such as initial eye position with cognitive factors to produce a salience representation or 'priority map' of the visual field, that combines salient visual features with behavioral goals (Gottlieb et al. 1998; Bisley and Goldberg 2010; Fiebelkorn and Kastner 2020; Chen et al. 2020). In macaques, neurons in area LIP signal the location of the visual target rather than the saccade goal (Gottlieb and Goldberg 1999), which has been suggested to dissociate between the locus of visual attention and the saccade motor plan. However, when visual presentation of the target and saccade execution were temporally separated, it was found that area LIP neurons first encoded the location of the visual cue, and later, some neurons also responded during saccade execution (Zhang and Barash 2000, 2004).

Whether marmoset PPC is also modulated by such cognitive factors is yet to be determined. However, there is 
evidence that marmosets can perform anti-saccades, a type of cognitively demanding visual task. Anti-saccade tasks typically require subjects to suppress a response to a salient, peripherally appearing stimulus, in favour of saccading to a featureless, unmarked location opposite this salient stimulus (Munoz and Everling 2004; Antoniades et al. 2013). In such tasks, the shape and/or colour of the central fixation point instructs the subject about whether the trial requires a saccade towards (pro-saccade) or away from (anti-saccade) the salient peripheral stimulus. Recently, (Johnston et al. 2019) observed that marmosets were capable of completing a slightly modified version of the traditional anti-saccade task, and that neurons in area LIP responded to both pro- and anti-saccade targets.

\section{Marmosets are capable of a wide range of visual behaviors}

Visual attention and saccadic eye movements are intimately linked from behavioural and anatomical perspectives. The spatial allocation of attention is tightly time-locked and precedes saccade execution (Filali-Sadouk et al. 2010), and to make a saccade towards an appropriate location, attention must be directed towards the spatial location of the saccade target. Anatomically, visual attention and saccadic behaviours recruit a common network in the primate visual system (reviewed in (Wardak et al. 2011)). In humans, fMRI has demonstrated activation of similar regions in the frontal and parietal cortices during saccades and visual attention shifts (Corbetta 1998; Nobre et al. 2000; Perry and Zeki 2000; DeSouza et al. 2003; Munoz and Everling 2004; de Haan et al. 2008).

Given the functional and neuro-anatomical similarities between marmosets and higher-order primates like macaques and humans, it is worth examining whether marmosets are an appropriate behavioural model for probing the frontal-parietal saccade network. For decades, macaques were the ideal model for psychophysical and behavioural paradigms in visual research, demonstrating an immense capacity to learn complex rules and concentrate for long periods of time. Marmosets, on the other hand, have fallen short of macaques on such behaviours-managing to complete approximately half as many trials as macaques, with sessions typically lasting 1-2 h (Mitchell et al. 2014; Hung et al. 2015; Chen et al. 2021). While this can largely be attributed to the type of task being relatively unnatural for marmosets, requiring extended fixation periods and head restraint, we are still in the early stages of learning the extent of their behavioural repertoire. However, with constant improvements in the efficiency and precision of neural data collection and our ability to combine data across sessions, this is no longer a significant limitation to the marmoset model. Marmosets also tend to excel under unrestrained conditions, and in natural free-viewing or visual discrimination tasks that are more actively engaging (Mitchell et al., 2014). As such, marmosets are the ideal candidate when utilizing such paradigms, especially considering the potential for using standard eye tracking to measure visual behaviour in freely moving subjects (Jendritza et al. 2021).

When considering performance under head restraint, the main sequence of saccadic eye movements in marmosets is similar to that observed in macaques and humans, with a linear relationship between the amplitude and peak velocity of saccades (Mitchell et al. 2014; Chen et al. 2021). However, the range to which marmosets can rotate their eyes away from a default central position, is far more restricted compared to macaques and humans (Mitchell et al. 2014; Chen et al. 2021). Marmosets make saccadic eye movements within ten degrees of their initial rest position (Mitchell et al. 2014). Express saccades, or saccades with very low latencies, can be elicited using a 'gap' saccade task, in which the central fixation point disappears prior to the saccade target onset. Humans, macaques, and marmosets all exhibit low-latency express saccades in a gap-saccade task (Ma et al. 2020; Chen et al. 2021). Marmosets can also perform smooth pursuit eye movements, in which the eye voluntarily tracks a moving target, with similar velocity and acceleration profiles to macaques and humans (Mitchell et al. 2015). In a motion-discrimination task, marmosets displayed similar speed-accuracy trade-offs to humans. Saccade errors and reaction times increased as the motion signal decreased (Cloherty et al. 2020). Together, these results show that the marmoset is a promising model for studying eye movement behavior.

As previously mentioned, marmosets are capable of completing a slightly modified version of the traditional anti-saccade task (Johnston et al. 2019). In this version of the task, anti-saccade trials were presented in an entirely separate block from pro-saccade trials, and marmosets made anti-saccades towards a small, dimly lit peripheral stimulus. This version of the anti-saccade task has not only been used in human studies (Barton et al. 2002; Edelman et al. 2006; Dafoe et al. 2007; Antoniades et al. 2013), it is also usually the final training stage for macaques - though (Johnston and Everling 2011) have previously noted that some macaques have also struggled advancing past this stage. While this version of the anti-saccade task did not require a geometric calculation of vector inversion of the location of the stimulus into a saccade command, it retained the most important clinical and cognitive components, such as response suppression, voluntary saccade generation, longer reaction times and higher error rates. These core components have been shown to require inhibition of the frontal-parietal saccade network (O’Driscoll et al. 1995; DeSouza et al. 2003).

Saccadic eye movement behaviors are closely linked to cognitive behaviors such as decision-making and visual 
attention. The extent to which marmoset saccade behavior is linked to cognitive behavior is still poorly understood. However, their eye movements are drawn to salient features of a visual stimulus, similar to macaques and humans. Primates tend to fixate salient features of an image, which may be driven by properties of the visual stimulus like color, luminance and motion (Chen et al. 2021) or be cognitively salient, like faces (Mitchell et al. 2014). Marmosets have also been proposed as a model for studying social behaviors (Miller et al. 2016; Nummela et al. 2017). In a free choice task, where marmosets choose between two saccade targets, marmosets were more likely to choose a target if they first viewed an image of a conspecific, with gaze oriented to one of the target locations (Spadacenta et al. 2019). This 'joint-attention' or reflexive gaze following behavior is also observed in humans and macaques, further illustrating that cognitive visual behaviors are homologous in the marmoset.

However, it is important to note that, to date, there has been little evidence that marmosets are capable of the same level of cognitive control as their macaque counterparts. Macaque studies have relied on training subjects to fixate for long durations (on the order of 2-3 s) while suppressing saccades to salient stimuli, whether this is a briefly flashed stimulus in a memory-guided saccade task (Andersen et al. 1990b), a stimulus cueing an anti-saccade away from the stimulus (Gottlieb and Goldberg 1999), or task that requires covertly searching an array of stimuli (Thompson et al. 1996; Wardak et al. 2006). To date, marmoset studies have yet to demonstrate delayed responses to visual stimuli. Fixation durations have been shorter (approximately 1 second, for example in (Ma et al. 2020)). The shorter fixation duration makes delayed-saccade tasks more challenging. Furthermore, it is still an open question whether marmosets can suppress saccades to peripheral targets for more than a few hundred milliseconds (Mitchell et al. 2014). As described above (Johnston et al. 2019), researchers settled on a modified version of the anti-saccade task. While the limits of marmoset behavioural training are still largely unknown, it is important to note that there are likely significant limitations on the types of cognitive visual tasks they can perform compared to macaques.

\section{Bridging the gap: from brain networks to behavior}

The next frontier in systems neuroscience is understanding not just how individual areas of the brain contribute to cognitive behavior, but how areas of the brain work together. Non-invasive imaging techniques, such as fMRI have the advantage of measuring physiological changes across the whole brain simultaneously. Functional imaging studies have revealed that FEF and area LIP are almost always co-activated in attention and saccade tasks in both humans (Corbetta 1998; Nobre et al. 2000; Perry and Zeki 2000; de Haan et al. 2008) and macaques (Koyama et al. 2004; Baker et al. 2006; Wardak et al. 2010). In marmosets, fMRI has revealed homologous networks for vision (Fig 3A) and saccadic eye movements (Fig 3B). A free-viewing task, in which videos of action movie trailers were displayed at different locations on a screen, revealed activation of visual cortical areas as well as frontal-parietal areas, with peaks in area LIP and area $8 \mathrm{aV}$. The same task in humans confirmed that activation peaked in area LIP and the FEF (Schaeffer et al. 2019). These findings built on an earlier study which found similar results while marmosets viewed static images, although the static images did not evoke as much parietal activity (Hung et al. 2015). Together, these studies lay the foundation for establishing homologous functional networks for visual behavior in the marmoset. Unfortunately, due to the long time-scale of the hemodynamic response, fMRI alone cannot provide insights into the cellular-level circuitry involved in inter-area communication.

In macaques, a growing number of studies have used multi-area extracellular recordings to look at temporal correlations in activity across nodes of the frontal-parietal network. These studies have given insights into how the timing of neural activity across nodes of the network contribute to behavior. For example, neurons in the frontal and parietal cortex signal task and choice information with the same latency (Siegel et al. 2015). Furthermore, temporally coherent neural activity across nodes of the frontal-parietal network is instrumental in guiding eye-hand coordination (Dean et al. 2012), decision-making (Pesaran et al. 2008; Wong et al. 2016) and visual attention (Buschman and Miller 2007; Saalmann et al. 2007, 2012; Gregoriou et al. 2009; Bastos et al. 2015; Fiebelkorn et al. 2018). However, large-scale optical imaging, multi-electrode and multi-area recordings are challenging in macaques, because they rely on access to the entire surface of the cortical areas in question, and most high-level extra-striate areas of the macaque visual system, like FEF and area LIP, lie partially obscured within sulci. Most imaging and multi-electrode studies in macaques have been conducted on earlier visual areas like V1, because they lie exposed and unobscured on the cortical surface (for example see (Chen and Seidemann 2012)) . Typically, such studies have found a homogeneous topographical layout of the visual field across these early visual areas, where neurons in adjacent columns have receptive fields that overlap regions of the retina. However, growing evidence suggests a more fractured and twisted topography exists in extra-striate areas. Notably, the lissencephalic marmoset cortex, which is uniquely suited to such large-scale optical imaging and multi-electrode investigations, has corroborated such evidence, finding a more twisted topography with regions of rapid change in receptive field positions 
Fig. 3 Networks for visual and saccade responses in the marmoset. A Visual response network in an example marmoset (left and right hemispheres shown). Functional MRI responses were compared between viewing static visual images and a fixation task (lateral, left and medial, right views shown). Adapted from (Hung et al. 2015). B Visuo-saccade network averaged across responses of three marmosets (1. Functional MRI responses were recorded while marmosets free-viewed videos displayed at different locations on a monitor. Adapted from (Schaeffer et al. 2019). M, Medial; R, Rostral
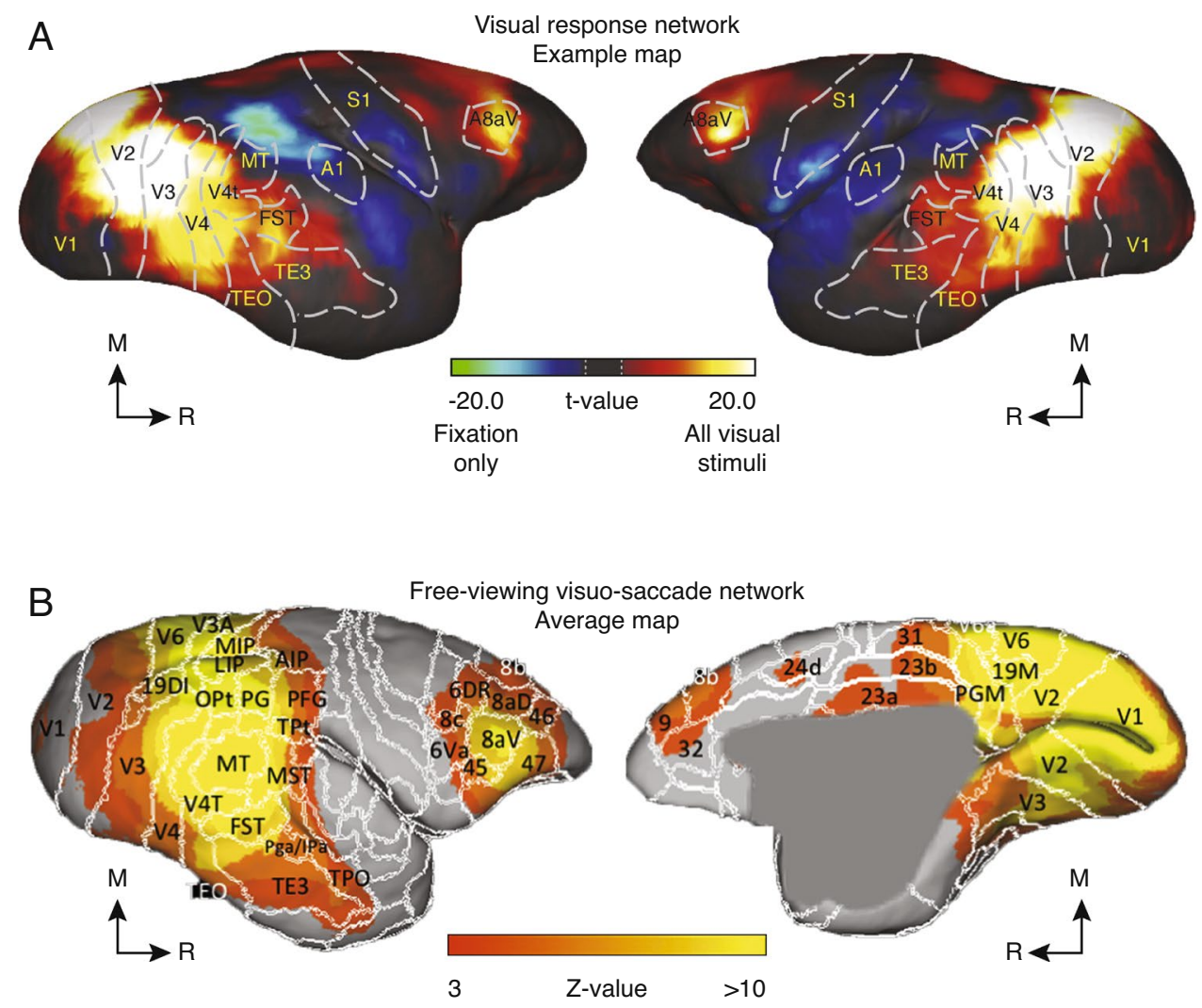

in extra-striate regions like the dorsomedial area (Yu et al. 2020). High-resolution fMRI maps of the macaque visual cortex have also depicted similar heterogeneous topographical layouts and retinotopic maps (Zhu and Vanduffel 2019). The middle temporal area, an area of the brain involved in encoding visual motion, is another example of an area obscured in macaque sulci, but exposed to the cortical surface in marmosets. High-density electrode array recordings from the middle temporal area of the marmoset have revealed population dynamics including neural correlations (Solomon et al. 2015), spatial encoding (Chen et al. 2015), and motion adaptation (Zavitz et al. 2016). Although they did not include population analyses, similar multi-electrode arrays have been used in both the frontal (Selvanayagam et al. 2019; Feizpour et al. 2021) and parietal (Ma et al. 2020) cortices of marmosets.

Furthermore, the marmoset lissencephalic cortex is well suited for linear electrode arrays which enable simultaneous recordings across cortical layers, when inserted perpendicular to the cortical surface. Such recordings are of importance when studying inter-area networks, as a canonical microcircuit has been traced within several neocortical areas, dictating how information is hierarchically processed in a sequential manner (Wiesel et al. 1974; Douglas et al. 1989; Douglas and Martin 2004; Shepherd 2011). Feedforward inputs from regions lower in the visual hierarchy synapse onto the intermediate layer and project up via excitatory neurons to the superficial layers, where they are then integrated with and modulated by feedback information from the same or higher-order cortical regions, before finally projecting to deeper layers (Malach et al. 1997; Solomon et al. 2002; Majaj et al. 2007) and ultimately projecting out to other cortical areas (Thomson and Bannister 2003). In macaque areas that lie on the cortical surface, such as area visual area 4 (V4), laminar-specific mechanisms have been revealed for visual attention (Nandy et al. 2017) and attention modulated V1-V4 communication in directed, laminar-specific manner (Ferro et al. 2021). Unfortunately, many areas of interest in the frontal-parietal network of macaques, including area LIP and parts of FEF are buried in sulci. It is possible to approach the macaque sulcal cortex from an angle that traverses all layers within a column (Schroeder et al. 1998), and a handful of studies have demonstrated the importance of this technique. For example, visual information varies across cortical layers in FEF (Chen et al. 2018) and the level of a subject's consciousness modulates laminar-specific activity between the thalamus, the FEF and area LIP (Redinbaugh et al. 2020). The marmoset offers a huge advantage in this research space, as a larger proportion of the visual cortex is exposed to the surface, including frontal and parietal areas. There are early examples of marmoset studies assessing cortical areas not accessible in the macaque for laminar recordings. For example, in the 
marmoset middle temporal area, such arrays have revealed different mechanisms of motion encoding in superficial and deep layers (Solomon et al. 2017). In marmoset frontal area $8 \mathrm{aD}$, laminar electrodes have been used to identify potential inhibitory mechanisms in an anti-saccade task (Johnston et al. 2019). As electrode technologies are rapidly evolving, marmosets are well positioned to address questions related to large-scale, multi-area population dynamics.

Extracellular electrophysiology alone has its limitations. Given that FEF and area LIP both receive input from several extra-striate visual areas (Andersen et al. 1990a; Schall 1991), conclusions about the temporal coherence of neural activity between areas of the frontal-parietal network are limited. It is difficult to dissociate functionally relevant signals from irrelevant ones, and to determine whether coherent fluctuations in two regions are simply due to common input. Furthermore, it is difficult to ascertain directionality in the flow of information across areas. Consequently, there is a need to perturb activity in one area, while recording from the other, to better understand the interactions between directly connected areas. One way to address this is by observing functional changes in a network associated with inactivation (pharmacologically or through cooling) or electrical micro-stimulation. Inactivating either FEF or area LIP (via cooling) while recording from the other changed the firing rate of over $70 \%$ of neurons during a memory-guided saccade task (Chafee and Goldman-Rakic 2000). Neurons in each area were equally likely to have firing rates augmented or suppressed, suggesting a fairly equal exchange of information across areas, while neural latencies to the cue response remained unchanged. Likewise, micro-stimulation of FEF results in widespread activation of neurons in area LIP (Ekstrom et al. 2008). Inactivation of both area LIP (Wardak et al. 2002) and FEF (Wardak et al. 2006) results in an increase in reaction time for the selection of a saccade target amongst distractors. However, the deficits increased with task difficulty only in area LIP (Wardak et al. 2002), suggesting a role in encoding visual salience. Representations of visual salience emerge earlier in area LIP than in FEF (Buschman and Miller 2007), suggesting that these signals may propagate from parietal to frontal cortices. Indeed, a recent study found that representations of visual salience in FEF disappeared when the PPC was pharmacologically inactivated (Chen et al. 2020). While these studies have provided invaluable insights, both inactivation and micro-stimulation are spatially crude and non-selectively engage large regions of cortex around the site of stimulation or inhibition. As a result, any observed effects from these techniques could encompass indirect pathways through neighbouring cortical regions. Furthermore, inactivation studies are temporally limited by the time course of the drug or cooling procedure. Therefore, there is a need for techniques that can manipulate neural activity with both spatial and temporal precision to tie neural activity of individual cells to the anatomical projections across areas.

\section{Optogenetics as tool for dissecting neural circuits}

Optogenetics offers a way to modulate direct functional links between anatomically connected areas through precise stimulation or inhibition of specific cell types within an area, while recording from another (Boyden et al. 2005). The technique operates under the same general principle of electrical stimulation, chemical cooling or chemical lesioning agents, but targets specific types of neurons made to express lightsensitive ion channels or pumps, called opsins, to change the polarisation of the cell in response to specific wavelengths of light (Deisseroth 2015). Commonly, illumination of bacteriorhodopsins and halorhodopsins results in hyperpolarisation, which inhibits neural activity, while illumination of channelrhodopsins typically results in depolarisation and action potentials. Briefly, these microbial opsin genes, incorporated into stable and non-replicating viral vectors such as adenoassociated viral (AAV) vectors, are injected into regions of interest, where they are able to efficiently transduce specific types of post-mitotic neurons in the vicinity of the injection. Optogenetic techniques have been predominantly implemented in mouse models, however, their use in primates is growing (as reviewed in (El-Shamayleh and Horwitz 2019) and (Diester et al. 2011)). By exploiting viruses incorporating cell-specific promoters, it has been possible to determine the contribution of different cell types, particularly excitatory and inhibitory cells (Cardin et al. 2009; De et al. 2020). This is important because computational modelling has suggested that temporally coherent neural activity is driven by windows of neural excitation and inhibition (Shewcraft et al. 2020). This opens the door to using optogenetics to probe network dynamics and their cellular origins. Rodent models have already been used to investigate how projections from the frontal cortex to thalamus modulate visual attention (Wimmer et al. 2015; Schmitt et al. 2017). However, the neurophysiology and behaviour of rodents and primates differ in many ways, making it difficult to translate discoveries in rodents to higher-order primates.

In macaques, optogenetics has been used to reveal causal links between neural activity and cognitive behaviours in a manner that effectively extends the result of previous electrical micro-stimulation studies. For example, in macaques trained to saccade to a salient target among distractors, optogenetic stimulation of area LIP increases the number of saccades to targets within the stimulated neurons' receptive field, and decreases those saccades' latency (Dai et al. 2014). (Gerits et al. 2012) observed a similar decrease in 
saccade latencies when optogenetically stimulating the arcuate nucleus in macaques performing a visually guided saccade discrimination task, but reported little to no change in performance accuracy or other saccade metrics such as amplitude. Optical stimulation of V1 neurons transfected with channelrhodopsin (ChR2) variants can generate saccades towards the receptive field of stimulated neurons in macaques trained to perform saccade-dependent visual discrimination tasks (Jazayeri et al. 2012). However, optogenetic stimulation of saccade modulation centres like FEF in macaques (Ohayon et al. 2013; Inoue et al. 2015), is often suboptimal at evoking eye movements with metrics identical to visual or electrical stimulation protocols. Optogenetically evoked saccades in macaques often do not reach the desired eccentricity and are not entirely accurate in their direction trajectories. This is because it is difficult to target all relevant cells in these areas, as optogenetic injections activate a smaller volume of tissue than electrical micro-stimulation and because much of the area is buried in the arcuate sulcus in macaques, making targeting optical stimulation difficult.

In macaques, optogenetic stimulation of FEF axon terminals in the superior colliculus can generate saccades towards the receptive field of stimulated FEF cells (Inoue et al. 2015), indicating that technique can be used to determine the influence of long-range projections. However, the latencies of these optogenetically evoked saccades (Inoue et al. 2015) appear to be 150-170 ms longer than saccades evoked by electrical micro-stimulation (Schiller and Stryker 1972; Bruce et al. 1985). This may be explained by the fact that optical suppression of axon terminals can have unintended consequences if suppressive opsins affect synaptic transmission in unpredictable and complex ways, especially when illuminated at high intensities or for longer durations (Mahn et al. 2016; Wiegert et al. 2017). Stimulation of axon terminals may even cause some back-propagated activation of indirect pathways influencing saccades (Inoue et al. 2015) or it can depolarise both inhibitory and excitatory neurons (Jazayeri et al. 2012). (Nassi et al. 2015) demonstrated this exact phenomenon, when attempting to optogenetically target excitatory neurons in the macaque $\mathrm{V} 1$, and indirectly exciting inhibitory neurons. As a means to overcome such a limitation, (Shewcraft et al. 2020) recently demonstrated the ability to optogenetically manipulate either excitatory or inhibitory activity alone, by carefully selecting stimulation parameters such as light pulse duration.

Marmosets are a promising animal model for studying how neural circuits give rise to certain complex brain states and behaviours, and this remains true for their use in optogenetic protocols. While optogenetic techniques have only recently been introduced in marmosets, the smaller size of marmoset brains (relative to other primates) is already showing to be a key advantage. Forelimb movements have been induced through blue-light optogenetic stimulation of the marmoset motor cortex (Ebina et al. 2019). Using a gene expression system that amplifies neuronal expression of a ChR2 opsin gene variant with fast kinetics, Ebina and colleagues stimulated the motor cortex through a relatively large cranial window. Given that this has previously been difficult to accomplish in macaques, due to the size of their motor cortex restricting light permeability through neural tissue, this demonstrates a unique benefit of the marmoset model.

The small brain size of marmosets is also showing promise for enabling long-range transduction of optogenetic constructs. (MacDougall et al. 2016) developed a novel method to induce rapid photo-stimulation in individual neurons, for several months, in awake behaving marmosets. They reported that along with successful transport of the virus, ChR2 opsins and fluorescent proteins were trafficked further along long-range pyramidal neuron projections in the marmoset, from the site of injection, enabling accurate tracing of neural circuits that are directly and causally activated during visual behaviours. In the months following injection, similar excitatory and inhibitory changes in neural activity during optogenetic stimulation in marmosets (MacDougall et al. 2016) as have been previously observed in mice (Sato et al. 2014) and macaques (Han et al. 2011).

There have already been demonstrations of the success of optogenetics for investigating neural circuits in the visual cortex of marmosets. Recently, optogenetic suppression of the axon terminals of V2 feedback projections to V1, revealed an overall reduction in marmoset $\mathrm{V} 1$ responses to visual stimuli, as well as a reduction in surround suppression, a property fundamental to V1 (Fig 4; (Nurminen et al. 2018)). In macaques, optogenetic stimulation of the koniocellular compartment of the macaque LGN, while recording from V1, they observed short latency neural responses evoked in the supra-granular layers of V1, to which they are known to project anatomically (Klein et al. 2016). This study demonstrates that optogenetics is a suitable technique for studying longer-range projections. The relatively smaller brain size of the marmoset compared to the macaque suggests that it will be particularly suitable for studying network interactions across cortical distances, including between areas of the frontal and parietal cortices.

Finally, coupling optogenetics with a powerful imaging technique like two-photon microscopy, can further improve investigations into neuronal circuit mechanisms. Two-photon microscopy permits in vivo visualisation of neural activity at high resolutions, deep into the cortex and for extended periods of time. Briefly, it is a fluorescence imaging technique that relies on the principle of a fluorophore absorbing two photons of light and emitting a longer wavelength of light which is known to scatter less and penetrate deeper through neural tissue. Two-photon imaging is already well established in rodents (Holtmaat et al. 2009; 


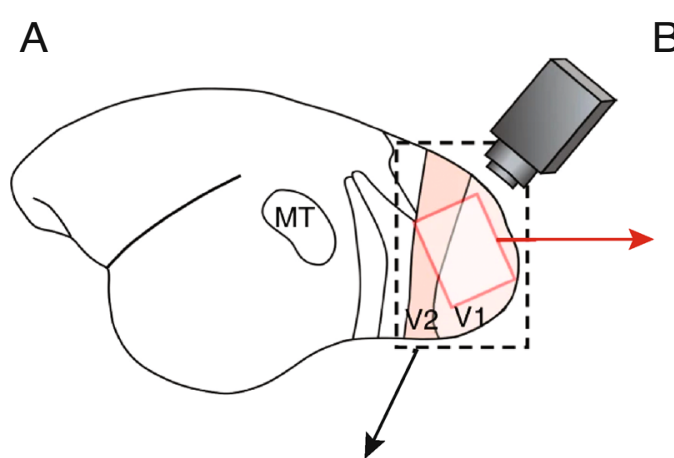

B
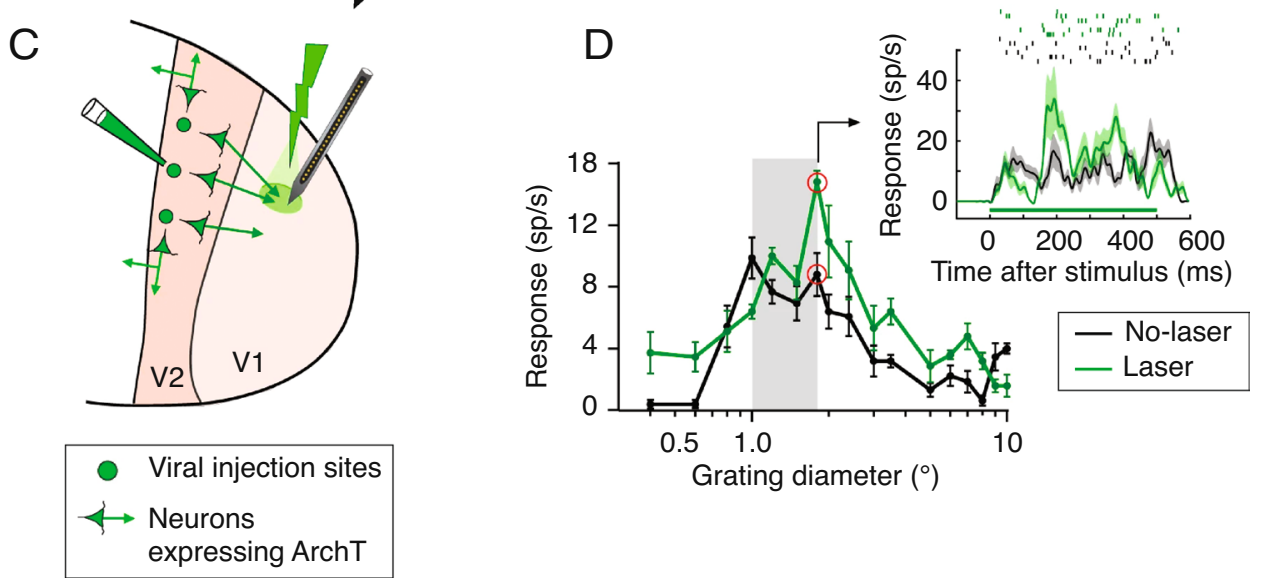

Fig. 4 Optogenetic manipulation of V2 feedback projections to V1 in the marmoset. A Schematic of the optical imaging procedure on a marmoset brain, with V1 and V2 boundaries highlighted. Red box: approximate location of the optically imaged region. B Example optical image of the cortical surface vasculature imaged under green light, identifying the V1/V2 border (white line). Green dots: reference positions for viral injections carrying optogenetic constructs. $\mathbf{C}$ Schematic of the optogenetic inactivation paradigm, with recording array and laser photo-stimulation over V1. Green dots: viral injec-

Drew et al. 2010), mainly due to their relatively thin dura, upper cortical layers, and amenability to transgenic technology - features shared by marmosets. While it has been attempted in the areas most exposed to the cortical surface in macaques, like V1 (Stettler et al. 2006; Heider et al. 2010), penetration depths in terms of anatomical layers are more limited owing to the cortical thickness and vascularisation. To date, fewer studies have attempted two-photon imaging in marmosets, however, studies in somatosensory (Sadakane et al. 2015) and motor cortical areas (Ebina et al. 2018) have successfully imaged hundreds of neurons for several months, up to cortical depths of $500 \mu \mathrm{m}$ (equating to layers 2/3) (Santisakultarm et al. 2016). Given the similarity in size and lissencephalic nature of the marmoset and mouse brains, it stands that the progress made in multi-area two-photon imaging in mice, using either multiple microscopes (Lecoq et al. 2014; Wagner et al. 2019) or a unique two-stage magnification process (Yang et al. 2019), is much more easily transferred to marmosets.

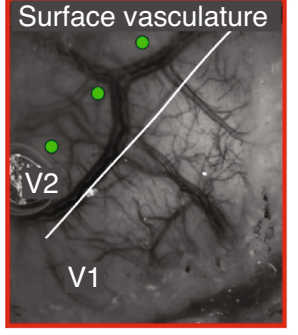

tion sites in V2 matching optical image in B. Green arrows: ArchTGFP expressing V2 neurons largely projecting back to V1. D Spatial summation curves for example V1 neuron recorded with (green) and without (black) laser stimulation. Grey area indicates the proximal surround of the V1 neuron. Inset: PSTH and raster plot measured at the stimulus diameters indicated by the red circles in the respective size-tuning curves of V1 neurons. Horizontal green line: laser-on time. Adapted from (Nurminen et al. 2018)

That being said, to date, this technology has been limited to single area imaging in macaques and marmosets.

\section{Conclusion and future directions}

Non-human primates have been essential in studying the neural mechanisms of cognitive behaviors, such as visual attention. However, there are still many open questions about how such behaviors arise from interactions across brain areas. New electrode technologies and molecular techniques like optogenetics continually increase the toolbox with which researchers can probe these questions. While macaques have historically been the dominant model in such investigations, given their extensive behavioural repertoire and our knowledge of their neurophysiology and neuroanatomy, the sulcal structure of their brain has been limiting in the application of such techniques. We propose that the marmoset monkey is the ideal primate model for this arsenal, and shows 
much promise to help bridge the gap between our anatomical knowledge of the structure of cortex and understanding how this precise architecture across brain areas gives rise to cognitive visual behavior. Combining optogenetic methods in marmosets with existing behavioural, multi-area neurophysiological, and neuroimaging approaches could help uncover the functional architecture underlying visual and cognitive behaviours in primates. However, because there is still a lot we do not know about marmoset neurophysiology and the extent of their behavioural capabilities, future research would greatly benefit from such investigations clarifying these gaps in our knowledge. Even if the current trajectory holds, and marmosets are restricted to more simple visual and cognitive behaviours, we argue that the benefits of their neuroanatomical and lissencephalic brain structure still provide important opportunities for the application of more complex techniques.

Funding This project was funded by the Australian Research Council (DE180100344 to MH; DP200100179 to NP and MH) and by the National Health and Medical Research Council of Australia (APP1185442 to MH). JD was also funded by the Australian Government Research Training Program (RTP) Stipend Scholarship.

\section{Declarations}

Conflicts of interest Not applicable.

Data availability Not applicable.

Code availability Not applicable.

Ethics approval Not applicable

Consent to participate Not applicable

Consent for publication Not applicable

Open Access This article is licensed under a Creative Commons Attribution 4.0 International License, which permits use, sharing, adaptation, distribution and reproduction in any medium or format, as long as you give appropriate credit to the original author(s) and the source, provide a link to the Creative Commons licence, and indicate if changes were made. The images or other third party material in this article are included in the article's Creative Commons licence, unless indicated otherwise in a credit line to the material. If material is not included in the article's Creative Commons licence and your intended use is not permitted by statutory regulation or exceeds the permitted use, you will need to obtain permission directly from the copyright holder. To view a copy of this licence, visit http://creativecommons.org/licenses/by/4.0/.

\section{References}

Andersen RA, Essick GK, Siegel RM (1985) Encoding of spatial location by posterior parietal neurons. Science $230: 456-458$
Andersen RA, Asanuma C, Essick G, Siegel RM (1990a) Corticocortical connections of anatomically and physiologically defined subdivisions within the inferior parietal lobule. J Comp Neurol 296:65-113

Andersen RA, Bracewell RM, Barash S et al (1990b) Eye position effects on visual, memory, and saccade-related activity in areas LIP and 7a of macaque. J Neurosci 10:1176-1196

Anderson JC, Kennedy H, Martin KAC (2011) Pathways of attention: synaptic relationships of frontal eye field to V4, lateral intraparietal cortex, and area 46 in macaque monkey. J Neurosci 31:10872-10881

Antoniades C, Ettinger U, Gaymard B et al (2013) An internationally standardised antisaccade protocol. Vision Res 84:1-5

Baker JT, Patel GH, Corbetta M, Snyder LH (2006) Distribution of activity across the monkey cerebral cortical surface, thalamus and midbrain during rapid, visually guided saccades. Cereb Cortex 16:447-459

Bakola S, Burman KJ, Rosa MGP (2015) The cortical motor system of the marmoset monkey (Callithrix jacchus). Neurosci Res 93:72-81

Barash S, Bracewell RM, Fogassi L et al (1991) Saccade-related activity in the lateral intraparietal area. II Spatial Properties J Neurophysiol 66:1109-1124

Barton JJS, Cherkasova MV, Lindgren K et al (2002) Antisaccades and task switching: studies of control processes in saccadic function in normal subjects and schizophrenic patients. Ann N Y Acad Sci 956:250-263

Bastos AM, Vezoli J, Bosman CA et al (2015) Visual areas exert feedforward and feedback influences through distinct frequency channels. Neuron 85:390-401

Berman RA, Joiner WM, Cavanaugh J, Wurtz RH (2009) Modulation of presaccadic activity in the frontal eye field by the superior colliculus. J Neurophysiol 101:2934-2942

Bisley JW, Goldberg ME (2003) Neuronal activity in the lateral intraparietal area and spatial attention. Science 299:81-86

Bisley JW, Goldberg ME (2010) Attention, intention, and priority in the parietal lobe. Annu Rev Neurosci 33:1-21

Blatt GJ, Andersen RA, Stoner GR (1990) Visual receptive field organization and cortico-cortical connections of the lateral intraparietal area (area LIP) in the macaque. J Comp Neurol 299:421-445

Blum B, Kulikowski JJ, Carden D, Harwood D (1982) Eye movements induced by electrical stimulation of the frontal fields of marmosets and squirrel monkeys. Brain Behav Evol 21:34-41

Boyden ES, Zhang F, Bamberg E et al (2005) Millisecond-timescale, genetically targeted optical control of neural activity. Nat Neurosci 8:1263-1268

Bruce CJ, Goldberg ME, Bushnell MC, Stanton GB (1985) Primate frontal eye fields. II. Physiological and anatomical correlates of electrically evoked eye movements. J Neurophysiol 54:714-734

Burman KJ, Palmer SM, Gamberini M, Rosa MGP (2006) Cytoarchitectonic subdivisions of the dorsolateral frontal cortex of the marmoset monkey (Callithrix jacchus), and their projections to dorsal visual areas. J Comp Neurol 495:149-172

Burman KJ, Bakola S, Richardson KE et al (2014a) Patterns of afferent input to the caudal and rostral areas of the dorsal premotor cortex (6DC and 6DR) in the marmoset monkey. J Comp Neurol 522:3683-3716

Burman KJ, Bakola S, Richardson KE et al (2014b) Patterns of cortical input to the primary motor area in the marmoset monkey. J Comp Neurol 522:811-843

Buschman TJ, Miller EK (2007) Top-down versus bottom-up control of attention in the prefrontal and posterior parietal cortices. Science 315:1860-1862 
Cardin JA, Carlén M, Meletis K et al (2009) Driving fast-spiking cells induces gamma rhythm and controls sensory responses. Nature 459:663-667

Cavanaugh J, Joiner WM, Wurtz RH (2012) Suppressive surrounds of receptive fields in monkey frontal eye field. J Neurosci 32:12284-12293

Chafee MV, Goldman-Rakic PS (2000) Inactivation of parietal and prefrontal cortex reveals interdependence of neural activity during memory-guided saccades. J Neurophysiol 83:1550-1566

Chaplin TA, Yu H-H, Soares JGM et al (2013) A conserved pattern of differential expansion of cortical areas in simian primates. $\mathrm{J}$ Neurosci 33:15120-15125

Chen Y, Seidemann E (2012) Attentional modulations related to spatial gating but not to allocation of limited resources in primate V1. Neuron 74:557-566

Chen M, Liu Y, Wei L, Zhang M (2013) Parietal cortical neuronal activity is selective for express saccades. J Neurosci 33:814-823

Chen SC, Morley JW, Solomon SG (2015) Spatial precision of population activity in primate area MT. J Neurophysiol 114:869-878

Chen M, Li B, Guang J et al (2016) Two subdivisions of macaque LIP process visual-oculomotor information differently. Proc Natl Acad Sci USA 113:E6263-E6270

Chen X, Zirnsak M, Moore T (2018) Dissonant representations of visual space in prefrontal cortex during eye movements. Cell Rep 22:2039-2052

Chen X, Zirnsak M, Vega GM et al (2020) Parietal cortex regulates visual salience and salience-driven behavior. Neuron 106:177187.e4

Chen C-Y, Matrov D, Veale R et al (2021) Properties of visually guided saccadic behavior and bottom-up attention in marmoset, macaque, and human. J Neurophysiol 125:437-457

Cloherty SL, Yates JL, Graf D et al (2020) Motion perception in the common marmoset. Cereb Cortex 30:2658-2672

Colby CL, Goldberg ME (1999) Space and attention in parietal cortex. Annu Rev Neurosci 22:319-349

Colby CL, Duhamel JR, Goldberg ME (1996) Visual, presaccadic, and cognitive activation of single neurons in monkey lateral intraparietal area. J Neurophysiol 76:2841-2852

Collins CE, Lyon DC, Kaas JH (2005) Distribution across cortical areas of neurons projecting to the superior colliculus in new world monkeys. Anat Rec A Discov Mol Cell Evol Biol 285:619-627

Corbetta M (1998) Frontoparietal cortical networks for directing attention and the eye to visual locations: identical, independent, or overlapping neural systems? Proc Natl Acad Sci USA 95:831-838

Corbetta M, Akbudak E, Conturo TE et al (1998) A common network of functional areas for attention and eye movements. Neuron 21:761-773

Dafoe JM, Armstrong IT, Munoz DP (2007) The influence of stimulus direction and eccentricity on pro- and anti-saccades in humans. Exp Brain Res 179:563-570

Dai J, Brooks DI, Sheinberg DL (2014) Optogenetic and electrical microstimulation systematically bias visuospatial choice in primates. Curr Biol 24:63-69

De A, El-Shamayleh Y, Horwitz GD (2020) Fast and reversible neural inactivation in macaque cortex by optogenetic stimulation of GABAergic neurons. Elife 9.: https://doi.org/10.7554/eLife. 52658

de Haan B, Morgan PS, Rorden C (2008) Covert orienting of attention and overt eye movements activate identical brain regions. Brain Res 1204:102-111

Dean HL, Hagan MA, Pesaran B (2012) Only coherent spiking in posterior parietal cortex coordinates looking and reaching. Neuron 73:829-841

Deisseroth K (2011) Optogenetics. Nat Methods 8:26-29
Deisseroth K (2015) Optogenetics: 10 years of microbial opsins in neuroscience. Nat Neurosci 18:1213-1225

DeSouza JFX, Menon RS, Everling S (2003) Preparatory set associated with pro-saccades and anti-saccades in humans investigated with event-related FMRI. J Neurophysiol 89:1016-1023

Diester I, Kaufman MT, Mogri M et al (2011) An optogenetic toolbox designed for primates. Nat Neurosci 14:387-397

Douglas RJ, Martin KAC (2004) Neuronal circuits of the neocortex. Annu Rev Neurosci 27:419-451

Douglas RJ, Martin KAC, Whitteridge D (1989) A canonical microcircuit for neocortex. Neural Comput 1:480-488

Drew PJ, Shih AY, Driscoll JD et al (2010) Chronic optical access through a polished and reinforced thinned skull. Nat Methods 7:981-984

Ebina T, Masamizu Y, Tanaka YR et al (2018) Two-photon imaging of neuronal activity in motor cortex of marmosets during upperlimb movement tasks. Nat Commun 9:1879

Ebina T, Obara K, Watakabe A et al (2019) Arm movements induced by noninvasive optogenetic stimulation of the motor cortex in the common marmoset. Proc Natl Acad Sci USA 116:22844-22850

Edelman JA, Valenzuela N, Barton JJS (2006) Antisaccade velocity, but not latency, results from a lack of saccade visual guidance. Vision Res 46:1411-1421

Ekstrom LB, Roelfsema PR, Arsenault JT et al (2008) Bottom-up dependent gating of frontal signals in early visual cortex. Science 321:414-417

El-Shamayleh Y, Horwitz GD (2019) Primate optogenetics: Progress and prognosis. Proc Natl Acad Sci USA. https://doi.org/10.1073/ pnas. 1902284116

Feizpour A, Majka P, Chaplin TA et al (2021) Visual responses in the dorsolateral frontal cortex of marmoset monkeys. J Neurophysiol 125:296-304

Ferrier D (1874) XVI. The Croonian Lecture.-experiments on the brain of monkeys (second series)

Ferro D, van Kempen J, Boyd M et al (2021) Directed information exchange between cortical layers in macaque V1 and V4 and its modulation by selective attention. Proc Natl Acad Sci USA 118.: https://doi.org/10.1073/pnas.2022097118

Fiebelkorn IC, Kastner S (2020) Functional specialization in the attention network. Annu Rev Psychol 71:221-249

Fiebelkorn IC, Pinsk MA, Kastner S (2018) A dynamic interplay within the frontoparietal network underlies rhythmic spatial attention. Neuron 99:842-853.e8

Filali-Sadouk N, Castet E, Olivier E, Zenon A (2010) Similar effect of cueing conditions on attentional and saccadic temporal dynamics. J vis 10(21):1-13

Fries W (1984) Cortical projections to the superior colliculus in the macaque monkey: a retrograde study using horseradish peroxidase. J Comp Neurol 230:55-76

Gerits A, Farivar R, Rosen BR et al (2012) Optogenetically induced behavioral and functional network changes in primates. Curr Biol 22:1722-1726

Ghahremani M, Hutchison RM, Menon RS, Everling S (2017) Frontoparietal functional connectivity in the common marmoset. Cereb Cortex 27:3890-3905

Gnadt JW, Andersen RA (1988) Memory related motor planning activity in posterior parietal cortex of macaque. Exp Brain Res $70: 216-220$

Gold JI, Shadlen MN (2000) Representation of a perceptual decision in developing oculomotor commands. Nature 404:390-394

Goldberg ME, Colby CL, Duhamel JR (1990) Representation of visuomotor space in the parietal lobe of the monkey. Cold Spring Harb Symp Quant Biol 55:729-739

Gottlieb J, Goldberg ME (1999) Activity of neurons in the lateral intraparietal area of the monkey during an antisaccade task. Nat Neurosci 2:906-912 
Gottlieb JP, Kusunoki M, Goldberg ME (1998) The representation of visual salience in monkey parietal cortex. Nature 391:481-484

Gregoriou GG, Gotts SJ, Zhou H, Desimone R (2009) High-frequency, long-range coupling between prefrontal and visual cortex during attention. Science 324:1207-1210

Han X, Chow BY, Zhou H et al (2011) A high-light sensitivity optical neural silencer: development and application to optogenetic control of non-human primate cortex. Front Syst Neurosci 5:18

Hanks TD, Ditterich J, Shadlen MN (2006) Microstimulation of macaque area LIP affects decision-making in a motion discrimination task. Nat Neurosci 9:682-689

Hawellek DJ, Wong YT, Pesaran B (2016) Temporal coding of rewardguided choice in the posterior parietal cortex. Proc Natl Acad Sci 113:13492-13497

Heider B, Nathanson JL, Isacoff EY et al (2010) Two-photon imaging of calcium in virally transfected striate cortical neurons of behaving monkey. PLoS One 5:e13829

Holtmaat A, Bonhoeffer T, Chow DK et al (2009) Long-term, highresolution imaging in the mouse neocortex through a chronic cranial window. Nat Protoc 4:1128-1144

Hook MA, Rogers LJ (2008) Visuospatial reaching preferences of common marmosets (Callithrix jacchus): an assessment of individual biases across a variety of tasks. J Comp Psychol 122:41-51

Huerta MF, Krubitzer LA, Kaas JH (1987) Frontal eye field as defined by intracortical microstimulation in squirrel monkeys, owl monkeys, and macaque monkeys. II Cortical Connections J Comp Neurol 265:332-361

Hung CC, Yen CC, Ciuchta JL et al (2015) Functional MRI of visual responses in the awake, behaving marmoset. Neuroimage 120:1-11

Inoue K-I, Takada M, Matsumoto M (2015) Neuronal and behavioural modulations by pathway-selective optogenetic stimulation of the primate oculomotor system. Nat Commun 6:8378

Isa $\mathrm{T}$ (2017) Using the common marmoset for neurophysiological studies of neocortical functions. J Physiol 595:7013

Jazayeri M, Lindbloom-Brown Z, Horwitz GD (2012) Saccadic eye movements evoked by optogenetic activation of primate V1. Nat Neurosci 15:1368-1370

Jendritza P, Klein FJ, Rohenkohl G, Fries P (2021) Visual neuroscience methods for marmosets: efficient receptive field mapping and head-free eye tracking. eneuro 8(3):ENEURO.0489-20.2021. https://doi.org/10.1523/ENEURO.0489-20.2021

Jerde TA, Curtis CE (2013) Maps of space in human frontoparietal cortex. J Physiol Paris 107:510-516

Johnston K, Ma L, Schaeffer L, Everling S (2019) Alpha oscillations modulate preparatory activity in marmoset area 8Ad. J Neurosci 39:1855-1866

Johnston K, Everling S (2011) Frontal cortex and flexible control of saccades. The Oxford handbook of eye movements

Klein C, Evrard HC, Shapcott KA et al (2016) Cell-targeted optogenetics and electrical microstimulation reveal the primate koniocellular projection to supra-granular visual cortex. Neuron 90:143-151

Koyama M, Hasegawa I, Osada T et al (2004) Functional magnetic resonance imaging of macaque monkeys performing visually guided saccade tasks: comparison of cortical eye fields with humans. Neuron 41:795-807

Kustov AA, Robinson DL (1996) Shared neural control of attentional shifts and eye movements. Nature 384:74-77

Kusunoki M, Gottlieb J, Goldberg ME (2000) The lateral intraparietal area as a salience map: the representation of abrupt onset, stimulus motion, and task relevance. Vision Res 40:1459-1468

Lecoq J, Savall J, Vučinić D et al (2014) Visualizing mammalian brain area interactions by dual-axis two-photon calcium imaging. Nat Neurosci 17:1825-1829
Ma L, Selvanayagam J, Ghahremani M et al (2020) Single-unit activity in marmoset posterior parietal cortex in a gap saccade task. $\mathrm{J}$ Neurophysiol 123:896-911

MacDougall M, Nummela SU, Coop S et al (2016) Optogenetic manipulation of neural circuits in awake marmosets. J Neurophysiol 116:1286-1294

Mahn M, Prigge M, Ron S et al (2016) Biophysical constraints of optogenetic inhibition at presynaptic terminals. Nat Neurosci 19:554-556

Majaj NJ, Carandini M, Movshon JA (2007) Motion integration by neurons in macaque MT is local, not global. J Neurosci 27:366-370

Majka P, Chaplin TA, Yu H-H et al (2016) Towards a comprehensive atlas of cortical connections in a primate brain: mapping tracer injection studies of the common marmoset into a reference digital template. J Comp Neurol 524:2161-2181

Majka P, Bai S, Bakola S et al (2020) Open access resource for cellularresolution analyses of corticocortical connectivity in the marmoset monkey. Nat Commun 11:1133

Malach R, Schirman TD, Harel M et al (1997) Organization of intrinsic connections in owl monkey area MT. Cereb Cortex 7:386-393

Mazzoni P, Bracewell RM, Barash S, Andersen RA (1996) Motor intention activity in the macaque's lateral intraparietal area. I. Dissociation of motor plan from sensory memory. J Neurophysiol 76:1439-1456

Meister MLR, Hennig JA, Huk AC (2013) Signal multiplexing and single-neuron computations in lateral intraparietal area during decision-making. J Neurosci 33:2254-2267

Miller CT, Wren Thomas A (2012) Individual recognition during bouts of antiphonal calling in common marmosets. J Comp Physiol A Neuroethol Sens Neural Behav Physiol 198:337-346

Miller CT, Freiwald WA, Leopold DA et al (2016) Marmosets: a neuroscientific model of human social behavior. Neuron 90:219-233

Mitchell JF, Leopold DA (2015) The marmoset monkey as a model for visual neuroscience. Neurosci Res 93:20-46

Mitchell JF, Reynolds JH, Miller CT (2014) Active vision in marmosets: a model system for visual neuroscience. J Neurosci 34:1183-1194

Mitchell JF, Priebe NJ, Miller CT (2015) Motion dependence of smooth pursuit eye movements in the marmoset. J Neurophysiol 113:3954-3960

Mohler CW, Goldberg ME, Wurtz RH (1973) Visual receptive fields of frontal eye field neurons. Brain Res 61:385-389

Mott FW, Schuster E, Halliburton WD (1910) Cortical lamination and localisation in the brain of the marmoset. Proc R Soc Lond B Biol Sci 82:124-134

Munoz DP, Everling S (2004) Look away: the anti-saccade task and the voluntary control of eye movement. Nat Rev Neurosci 5:218-228

Nandy AS, Nassi JJ, Reynolds JH (2017) Laminar organization of attentional modulation in macaque visual area V4. Neuron 93:235-246

Nassi JJ, Avery MC, Cetin AH et al (2015) Optogenetic activation of normalization in alert macaque visual cortex. Neuron 86:1504-1517

Nobre AC, Gitelman DR, Dias EC, Mesulam MM (2000) Covert visual spatial orienting and saccades: overlapping neural systems. Neuroimage 11:210-216

Nummela SU, Jovanovic V, de la Mothe L, Miller CT (2017) Social context-dependent activity in marmoset frontal cortex populations during natural conversations. J Neurosci 37:7036-7047

Nurminen L, Merlin S, Bijanzadeh M et al (2018) Top-down feedback controls spatial summation and response amplitude in primate visual cortex. Nat Commun 9:2281

O'Driscoll GA, Alpert NM, Matthysse SW et al (1995) Functional neuroanatomy of antisaccade eye movements investigated with positron emission tomography. Proc Natl Acad Sci USA 92:925-929 
Ohayon S, Grimaldi P, Schweers N, Tsao DY (2013) Saccade modulation by optical and electrical stimulation in the macaque frontal eye field. J Neurosci 33:16684-16697

Paré M, Wurtz RH (1997) Monkey posterior parietal cortex neurons antidromically activated from superior colliculus. J Neurophysiol 78:3493-3497

Parker AJ, Newsome WT (1998) Sense and the single neuron: probing the physiology of perception. Annu Rev Neurosci 21:227-277

Perry RJ, Zeki S (2000) The neurology of saccades and covert shifts in spatial attention: an event-related fMRI study. Brain 123(Pt 11):2273-2288

Pesaran B, Nelson MJ, Andersen RA (2008) Free choice activates a decision circuit between frontal and parietal cortex. Nature 453:406-409

Petrides M, Pandya DN (2002) Comparative cytoarchitectonic analysis of the human and the macaque ventrolateral prefrontal cortex and corticocortical connection patterns in the monkey. Eur J Neurosci 16:291-310

Petrides M, Cadoret G, Mackey S (2005) Orofacial somatomotor responses in the macaque monkey homologue of Broca's area. Nature 435:1235-1238

Platt ML, Glimcher PW (1999) Neural correlates of decision variables in parietal cortex. Nature 400:233-238

Premereur E, Janssen P, Vanduffel W (2013) FEF-microstimulation causes task-dependent modulation of occipital fMRI activity. Neuroimage 67:42-50

Redinbaugh MJ, Phillips JM, Kambi NA et al (2020) Thalamus modulates consciousness via layer-specific control of cortex. Neuron 106:66-75.e12

Reser DH, Burman KJ, Yu HH et al (2013) Contrasting patterns of cortical input to architectural subdivisions of the area 8 complex: A retrograde tracing study in marmoset monkeys. Cereb Cortex 23:1901-1922

Robinson DA, Fuchs AF (1969) Eye movements evoked by stimulation of frontal eye fields. J Neurophysiol 32:637-648

Rosa MGP, Palmer SM, Gamberini M et al (2009) Connections of the dorsomedial visual area: pathways for early integration of dorsal and ventral streams in extrastriate cortex. J Neurosci 29:4548-4563

Saalmann YB, Pigarev IN, Vidyasagar TR (2007) Neural mechanisms of visual attention: how top-down feedback highlights relevant locations. Science 316:1612-1615

Saalmann YB, Pinsk MA, Wang L et al (2012) The pulvinar regulates information transmission between cortical areas based on attention demands. Science 337:753-756

Sadakane O, Masamizu Y, Watakabe A et al (2015) Long-term twophoton calcium imaging of neuronal populations with subcellular resolution in adult non-human primates. Cell Rep 13:1989-1999

Santisakultarm TP, Kersbergen CJ, Bandy DK et al (2016) Two-photon imaging of cerebral hemodynamics and neural activity in awake and anesthetized marmosets. J Neurosci Methods 271:55-64

Sasaki E, Suemizu H, Shimada A et al (2009) Generation of transgenic non-human primates with germline transmission. Nature 459:523-527

Sato TK, Häusser M, Carandini M (2014) Distal connectivity causes summation and division across mouse visual cortex. Nat Neurosci 17:30-32

Schaeffer DJ, Gilbert KM, Hori Y et al (2019) Task-based fMRI of a free-viewing visuo-saccadic network in the marmoset monkey. Neuroimage 202:116147

Schall JD (1991) Neuronal activity related to visually guided saccades in the frontal eye fields of rhesus monkeys: comparison with supplementary eye fields. J Neurophysiol 66:559-579

Schall JD, Morel A, King DJ, Bullier J (1995) Topography of visual cortex connections with frontal eye field in macaque: convergence and segregation of processing streams. J Neurosci 15(4464):4487

Schall JD, Zinke W, Cosman JD et al (2020) On the Evolution of the Frontal Eye Field: Comparisons of Monkeys, Apes, and Humans. In: Evolutionary Neuroscience. Elsevier, pp 861-890

Schiller PH, Stryker M (1972) Single-unit recording and stimulation in superior colliculus of the alert rhesus monkey. J Neurophysiol 35:915-924

Schmitt LI, Wimmer RD, Nakajima M et al (2017) Thalamic amplification of cortical connectivity sustains attentional control. Nature 545:219-223

Schmolesky MT, Wang Y, Hanes DP et al (1998) Signal timing across the macaque visual system. J Neurophysiol 79:3272-3278

Schroeder CE, Mehta AD, Givre SJ (1998) A spatiotemporal profile of visual system activation revealed by current source density analysis in the awake macaque. Cereb Cortex 8:575-592

Selvanayagam J, Johnston KD, Schaeffer DJ et al (2019) Functional localization of the frontal eye fields in the common marmoset using microstimulation. J Neurosci 39:9197-9206

Shepherd GM (2011) The microcircuit concept applied to cortical evolution: from three-layer to six-layer cortex. Front Neuroanat 5:30

Shewcraft RA, Dean HL, Fabiszak MM et al (2020) Excitatory/ inhibitory responses shape coherent neuronal dynamics driven by optogenetic stimulation in the primate brain. J Neurosci 40:2056-2068

Shibutani H, Sakata H, Hyvärinen J (1984) Saccade and blinking evoked by microstimulation of the posterior parietal association cortex of the monkey. Exp Brain Res 55:1-8

Siegel M, Buschman TJ, Miller EK (2015) Cortical information flow during flexible sensorimotor decisions. Science 348:1352-1355

Silver MA, Kastner S (2009) Topographic maps in human frontal and parietal cortex. Trends Cogn Sci 13:488-495

Snyder LH, Batista AP, Andersen RA (1997) Coding of intention in the posterior parietal cortex. Nature 386:167-170

Solomon SG, Rosa MGP (2014) A simpler primate brain: the visual system of the marmoset monkey. Front Neural Circuits 8:96

Solomon SG, White AJR, Martin PR (2002) Extraclassical receptive field properties of parvocellular, magnocellular, and koniocellular cells in the primate lateral geniculate nucleus. J Neurosci 22:338-349

Solomon SS, Chen SC, Morley JW, Solomon SG (2015) Local and global correlations between neurons in the middle temporal area of primate visual cortex. Cereb Cortex 25:3182-3196

Solomon SS, Morley JW, Solomon SG (2017) Spectral signatures of feedforward and recurrent circuitry in monkey area MT. Cereb Cortex 27:2793-2808

Sommer MA, Wurtz RH (2006) Influence of the thalamus on spatial visual processing in frontal cortex. Nature 444:374-377

Spadacenta S, Dicke PW, Thier P (2019) Reflexive gaze following in common marmoset monkeys. Sci Rep 9:15292

Stanton GB, Deng SY, Goldberg ME, McMullen NT (1989) Cytoarchitectural characteristic of the frontal eye fields in macaque monkeys. J Comp Neurol 282:415-427

Stanton GB, Bruce CJ, Goldberg ME (1995) Topography of projections to posterior cortical areas from the macaque frontal eye fields. J Comp Neurol 353:291-305

Stettler DD, Yamahachi H, Li W et al (2006) Axons and synaptic boutons are highly dynamic in adult visual cortex. Neuron 49:877-887

Sugrue LP, Corrado GS, Newsome WT (2004) Matching behavior and the representation of value in the parietal cortex. Science 304:1782-1787

Thier P, Andersen RA (1998) Electrical microstimulation distinguishes distinct saccade-related areas in the posterior parietal cortex. J Neurophysiol 80:1713-1735 
Thompson KG, Hanes DP, Bichot NP, Schall JD (1996) Perceptual and motor processing stages identified in the activity of macaque frontal eye field neurons during visual search. J Neurophysiol 76:4040-4055

Thomson AM, Bannister AP (2003) Interlaminar connections in the neocortex. Cereb Cortex 13:5-14

Wagner MJ, Kim TH, Kadmon J et al (2019) Shared cortex-cerebellum dynamics in the execution and learning of a motor task. Cell 177:669-682.e24

Walker AE (1940) A cytoarchitectural study of the prefrontal area of the macaque monkey. J Comp Neurol 73:59-86

Wardak C, Olivier E, Duhamel J-R (2002) Saccadic target selection deficits after lateral intraparietal area inactivation in monkeys. J Neurosci 22:9877-9884

Wardak C, Ibos G, Duhamel J-R, Olivier E (2006) Contribution of the monkey frontal eye field to covert visual attention. J Neurosci 26:4228-4235

Wardak C, Vanduffel W, Orban GA (2010) Searching for a salient target involves frontal regions. Cereb Cortex 20:2464-2477

Wardak C, Olivier E, Duhamel J-R (2011) The relationship between spatial attention and saccades in the frontoparietal network of the monkey. Eur J Neurosci 33:1973-1981

Whissell PD, Tohyama S, Martin LJ (2016) The use of DREADDs to deconstruct behavior. Front Genet 7:70

Wiegert JS, Mahn M, Prigge M et al (2017) Silencing neurons: tools, applications, and experimental constraints. Neuron 95:504-529

Wiesel TN, Hubel DH, Lam DM (1974) Autoradiographic demonstration of ocular-dominance columns in the monkey striate cortex by means of transneuronal transport. Brain Res 79:273-279
Wimmer RD, Schmitt LI, Davidson TJ et al (2015) Thalamic control of sensory selection in divided attention. Nature 526:705-709

Wong YT, Fabiszak MM, Novikov Y et al (2016) Coherent neuronal ensembles are rapidly recruited when making a look-reach decision. Nat Neurosci 19:327-334

Wurtz RH, Mohler CW (1976) Enhancement of visual responses in monkey striate cortex and frontal eye fields. J Neurophysiol 39:766-772

Yang M, Zhou Z, Zhang J et al (2019) MATRIEX imaging: multi-area two-photon real-time in-vivo explorer. bioRxiv 510545

Yu H-H, Rowley DP, Price NSC et al (2020) A twisted visual field map in the primate dorsomedial cortex predicted by topographic continuity. Sci Adv 6.: https://doi.org/10.1126/sciadv.aaz8673

Zavitz E, Yu H-H, Rowe EG et al (2016) Rapid adaptation induces persistent biases in population codes for visual motion. J Neurosci 36:4579-4590

Zhang M, Barash S (2000) Neuronal switching of sensorimotor transformations for antisaccades. Nature 408:971-975

Zhang M, Barash S (2004) Persistent LIP activity in memory antisaccades: working memory for a sensorimotor transformation. J Neurophysiol 91:1424-1441

Zhu Q, Vanduffel W (2019) Submillimeter fMRI reveals a layout of dorsal visual cortex in macaques, remarkably similar to new world monkeys. Proc Natl Acad Sci U S A 116:2306-2311

Publisher's Note Springer Nature remains neutral with regard to jurisdictional claims in published maps and institutional affiliations. 